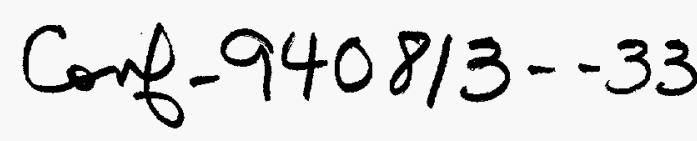

PNL-SA-25345

\title{
A SOLUBILITY MODEL FOR AMORPHOUS SILICA IN CONCENTRATED ELECTROLYTES
}

\author{
A. R. Felmy \\ C. C. Schroeder \\ M. J. Mason
}

August 1994

Presented at the

Symposium of Scientific Issues Related to Safety and Treatment of Hanford Waste Tanks

August 21-26, 1994

Washington, D.C.

Prepared for

the U.S. Department of Energy

under Contract DE-AC06-76RLO 1830

Pacific Northwest Laboratory

Richland, Washington 99352

\section{DISCLAIMER}

This report was prepared as an account of work sponsored by an agency of the United States Government. Neither the United States Government nor any agency thereof, nor any of their employees, makes any warranty, express or implied, or assumes any legal liability or responsibility for the accuracy, completeness, or usefulness of any information, apparatus, product, or process disclosed, or represents that its use would not infringe privately owned rights. Reference herein to any specific commercial product, process, or service by trade name, trademark, manufacturer, or otherwise does not necessarily constitute or imply its endorsement, recommendation, or favoring by the United States Government or any agency thereof. The views and opinions of authors expressed herein do not necessarily state or reflect those of the United States Government or any agency thereof. 


\section{DISCLAIMER}

Portions of this document may be illegible in electronic image products. Images are produced from the best available original document. 


\title{
A Solubility Model for Amorphous Silica
} in Concentrated Electrolytes

\author{
A.R. Felmy \\ C.C. Schroeder \\ M.J. Mason \\ Pacific Northwest Laboratory(a) \\ Richland, WA 99352
}

\section{ABSTRACT}

This paper describes the development of an aqueous thermodynamic model for accurately predicting the solubility of amorphous silica and other silicacontaining compounds in the system $\mathrm{Na}^{+}-\mathrm{H}^{+}-\mathrm{Mg}^{2+}-\mathrm{NO}_{3}^{-}-\mathrm{SO}_{4}^{2-}-\mathrm{Cl}^{-}-\mathrm{H}_{2} \mathrm{O}$ to high concentration and across the temperature range $25-100^{\circ} \mathrm{C}$. This model, which utilizes the aqueous thermodynamic model of Pitzer, includes only one dissolved silica species, $\mathrm{H}_{4} \mathrm{SiO}_{4}(\mathrm{aq})$, and is valid in neutral to very acidic solutions. The model is parametrized from the extensive set of solubility data in the literature as well as from new experimental data on amorphous silica solubility in $\mathrm{HNO}_{3}$ and $\mathrm{HCL}$ developed as part of this study. The accuracy of the model is tested on solutions more complex than those used in model parameterization.

(a) Pacific Northwest Laboratory is operated for the U.S. Department of Energy by Battelle Memorial Institute Under Contract DE-AC06-76RLO 1830. 


\section{INTRODUCTION}

Silica is one of the major constituents of the earth's crust and is ubiquitously present in most natural materials. The solubility of silica and other silica-containing compounds is, therefore, of primary concern in geochemistry and in chemical processing applications where silica scale formation, resulting from changes in temperature and electrolyte composition, can cause problems in process design and operation. Unfortunately, the solubility of amorphous silica $\left(\mathrm{SiO}_{2}(\mathrm{am})\right)$ and other silica-containing compounds is strongly dependent on temperature and electrolyte composition. Hence, accurate experimental and thermodynamic data are required to predict the solubilities of silicate phases for geochemical or chemical engineering application.

In aqueous solutions of $\mathrm{pH}<9$, the principal dissolved silica species is silicic acid $\mathrm{H}_{4} \mathrm{SiO}_{4}(\mathrm{aq})$. It is the interactions of silicic acid with the other bulk chemical species (such as $\mathrm{Na}^{+}, \mathrm{NO}_{3}^{-}, \mathrm{Cl}^{-}$) in aqueous solutions that will determine the solubility of amorphous silica and other silica-containing compounds under neutral and acidic conditions. In this study, we developed a set of temperature-dependent ion interaction parameters for silicic acid with important bulk chemical species in order to accurately predict the solubility of amorphous silica in the system $\mathrm{Na}^{+}-\mathrm{H}^{+}-\mathrm{Mg}^{2+}-\mathrm{NO}_{3}^{-}-\mathrm{SO}_{4}^{2-}-\mathrm{Cl}^{-}-\mathrm{H}_{2} \mathrm{O}$ to high concentration and over the temperature range $25-100^{\circ} \mathrm{C}$. Such a model is also necessary for predicting the solubility of more complex silica-containing compounds, such as aluminum silicates. This model was developed from the extensive set of solubility data for amorphous silica present in the literature (Marshall 1980a,b; Marshall and Warakomski 1980; Chen and Marshall 1982; Marshall and Chen 1982a,b; Elmer and Nordberg 1958) as well as solubility data on amorphous silica in $\mathrm{HNO}_{3}$ and $\mathrm{HCl}$ obtained as part of this study. 


\section{EXPERIMENTAL PROCEDURES}

The experimental procedure used in this study was the same as that used by Marshall and Warakomski (1980). Briefly, the procedure consisted of suspending $4 \mathrm{~g}$ of silica gel (Baker analyzed reagent) in $30-\mathrm{mL}$ of either $\mathrm{HNO}_{3}$, $\mathrm{HCl}$, or $\mathrm{NaNO}_{3} \mathrm{placed}$ in $50-\mathrm{mL}$ centrifuge tubes. The $\mathrm{HNO}_{3}, \mathrm{HCl}$, or $\mathrm{NaNO}_{3}$ ranged in concentration from $0.0001 \mathrm{M}$ to 2.0M. Only four $\mathrm{NaNO}_{3}$ samples were included. These samples were used to check our results against the results of Marshal1 (1980a). The silica gel had been previously washed with deionized water and air-dried overnight. The silica suspensions were placed on an orbital shaker and continuously shaken. Studies were conducted both at room temperature $\left(22-23^{\circ} \mathrm{C}\right)$ and at $47^{\circ} \mathrm{C}$. The studies at $47^{\circ} \mathrm{C}$ were conducted only in $\mathrm{HCl}$ because data were available in the literature for $\mathrm{HNO}_{3}$ at $36^{\circ} \mathrm{C}$ and $65^{\circ} \mathrm{C}$. The room temperature suspensions were sampled after 7 and 37 days equilibration. The $47^{\circ} \mathrm{C}$ suspensions were sampled after 7 and 38 days equilibration.

Sampling consisted of centrifugation at $2000 \mathrm{~g}$ for 7 to 10 minutes followed by filtration through Amicon-type F-25 Centrif10 membrane cones with an approximate pore size of $0.0018 \mu \mathrm{m}$. The filters were pretreated by soaking and rinsing in deionized water. A small aliquot of the sample was then passed through each filter to saturate any possible adsorption sites (this aliquot was discarded), followed by sufficient solution to analytically determine silica. Silica was analyzed by inductively coupled plasma spectroscopy (ICP).

\section{THERMODYMAMIC MODEL}

The aqueous thermodynamic model of Pitzer (1979) was utilized throughout this study to account for the variations in the activity coefficients of neutral and dissolved species. The exact equations used have been described in detail elsewhere (see Felmy and Weare 1986; Felmy et al. 1989, Pitzer 1979). In this study the most important ion-interaction parameters involve interactions between the electrolyte ions (i.e. $\mathrm{Na}^{+}, \mathrm{NO}_{3}^{-}, \mathrm{SO}_{4}^{2-} \ldots$ ) and the 
dominant aqueous silica species under neutral and acidic conditions, $\mathrm{H}_{4} \mathrm{SiO}_{4}(\mathrm{aq})$. In terms of the Pitzer model, these ion-interaction parameters are those describing neutral-cation, neutral-anion, and neutral-cation-anion interactions. For example, in $\mathrm{NaCl}$ solutions these parameters would be $\lambda\left(\mathrm{H}_{4} \mathrm{SiO}_{4}-\mathrm{Na}^{+}\right), \lambda\left(\mathrm{H}_{4} \mathrm{SiO}_{4}-\mathrm{Cl}^{-}\right)$, and possibly $\lambda\left(\mathrm{H}_{4} \mathrm{SiO}_{4}-\mathrm{Na}^{+}-\mathrm{Cl}^{-}\right)$. In addition, to develop an accurate thermodynamic model requires knowledge of the important electrolyte ion-interaction parameters $\left(\beta^{0}, \beta^{1}\right.$, and $\left.\phi^{\phi}\right)$ to describe binary ion-interactions like $\mathrm{Na}^{+}-\mathrm{Cl}^{-}$and common-ion ternary ion-interactions $(\theta$ and 4) like $\mathrm{Na}^{+}-\mathrm{K}^{+}-\mathrm{Cl}^{-}$, as a function of temperature. The electrolyte ioninteraction parameters do not directiy affect the calculated activity coefficient of $\mathrm{H}_{4} \mathrm{SiO}_{4}(\mathrm{aq})$ but do affect the calculated activity of water. The activity of water can affect the solubility calculations for amorphous silica at high electrolyte concentration via the rxn,

$$
\mathrm{SiO}_{2}(\mathrm{am})+2 \mathrm{H}_{2} \mathrm{O} \rightleftharpoons \mathrm{H}_{4} \mathrm{SiO}_{4}(\mathrm{aq})
$$

All of the ion-interaction parameters and standard chemical potentials developed or utilized in this study were fit to the following empirical temperature-dependent expression (see M $\phi 11$ er 1988),

$$
\begin{gathered}
P(T)=a_{1}+a_{2} T+a_{3} / T+a_{4} \ln T+a_{5} /(T-263)+a_{6} T^{2}+ \\
a_{7} /(680 .-T)+a_{8} /(T-227)
\end{gathered}
$$

where $P(T)$ is a temperature-dependent ion-interaction parameter or standard chemical potential. The necessary coefficients in eqn(2) for the Debye-Huckel $A^{\phi}$ term and the standard chemical potential of $\mathrm{H}_{2} \mathrm{O}(1)$ were taken from Greenberg and M $\$ 1$ ler (1989). The coefficients for eqn(2) for the $\mathrm{NaCl}$ and $\mathrm{Na}_{2} \mathrm{SO}_{4}$ ion-interaction parameters were also taken from Greenberg and $M \phi 1$ ler (1989). A complete listing of the other coefficients of eqn (2) used in this study is given in Table 1. A brief description of the method used to calculate these coefficients follows.

The coefficients for $\mathrm{HCl}$ were determined by calculating the values of $\beta^{0}, \beta^{1}$, and $C^{\phi}$ at $5^{\circ} \mathrm{C}$ intervals using the temperature- and density-dependent 
TABLE 1. Coefficients for the temperature dependent expression for electrolyte ion-interaction parameters.

$\begin{array}{rcccccc}\text { Parameter } & \underline{a}_{1} & \underline{a}_{2} & \underline{a}_{3} & \underline{a}_{4} & \underline{\mathrm{a}}_{6} \\ \mathrm{HCl} & \left(\beta^{0}\right) & -5.109945 \mathrm{e}+00 & -2.73385 \mathrm{e}-03 & 1.188690 \mathrm{e}+02 & 9.780609 \mathrm{e}-01 & 1.469778 \mathrm{e}-06 \\ & \left(\beta^{1}\right) & 9.9847059 \mathrm{e}+02 & 5.424992 \mathrm{e}-01 & -2.21692 \mathrm{e}+04 & -1.86027 \mathrm{e}+02 & -2.88597 \mathrm{e}-04 \\ & \left(C^{\phi}\right) & 3.8062945 \mathrm{e}-01 & 4.132298 \mathrm{e}-04 & -2.35792 \mathrm{e}+00 & -8.12431 \mathrm{e}-02 & -3.30966 \mathrm{e}-07 \\ & & & & & \\ \mathrm{HNO}_{3} & \left(\beta^{0}\right) & -5.650010 \mathrm{e}-01 & 4.388300 \mathrm{e}-03 & - & - & -6.95000 \mathrm{e}-06 \\ & \left(\beta^{1}\right) & -1.116200 \mathrm{e}-01 & 1.339600 \mathrm{e}-03 & - & - & - \\ & \left(C^{\phi}\right) & 4.4287000 \mathrm{e}-03 & -5.79520 \mathrm{e}-05 & - & - & 8.160000 \mathrm{e}-08 \\ \mathrm{MgSO}_{4} & \left(\beta^{0}\right) & 4.2672400 \mathrm{e}-01 & -6.90000 \mathrm{e}-04 & - & - & - \\ & \left(\beta^{1}\right) & -1.218700 \mathrm{e}+00 & 1.530000 \mathrm{e}-02 & - & - & - \\ & \left(\beta^{2}\right) & 3.8202000 \mathrm{e}+01 & -2.53000 \mathrm{e}-01 & - & - & - \\ & \left(C^{\phi}\right) & -1.300380 \mathrm{e}-01 & 5.200000 \mathrm{e}-04 & - & - & - \\ \mathrm{NaNO}_{3} & \left(\beta^{0}\right) & -1.315403 \mathrm{e}-01 & 4.538667 \mathrm{e}-04 & - & - & - \\ & \left(\beta^{1}\right) & -1.000309 \mathrm{e}+00 & 4.049333 \mathrm{e}-03 & - & - & - \\ & \left(C^{\phi}\right) & 1.1951454 \mathrm{e}-02 & -4.03764 \mathrm{e}-05 & - & - & - \\ \mathrm{MgCl}_{2} & \left(\beta^{0}\right) & 5.7606600 \mathrm{e}-01 & -9.31654 \mathrm{e}-04 & - & - & 5.939150 \mathrm{e}-07 \\ & \left(\beta^{1}\right) & 2.6013500 \mathrm{e}+00 & -1.09438 \mathrm{e}-02 & & & 2.601690 \mathrm{e}-05 \\ & \left(C^{\phi}\right) & 6.5786700 \mathrm{e}-02 & -2.89125 \mathrm{e}-04 & & & 3.018230 \mathrm{e}-07\end{array}$

equation given by Holmes et a1. (1987) and then refitting these calculated values to eqn(2). The coefficients for $\mathrm{HNO}_{3}$ were calculated from the first and second derivatives with respect to temperature given for $\beta^{0}, \beta^{1}$, and $\phi^{\phi}$ by Clegg and Brimblecombe (1990). In a similar fashion the coefficients for $\mathrm{MgSO}_{4}$ were calculated from the first derivative with respect to temperature expression given by Pitzer (1979). The coefficients for $\mathrm{MgCl}_{2}$ were taken from Delima and Pitzer (1983). The values of $\mathrm{NaNO}_{3}$ were calculated at $25^{\circ} \mathrm{C}$ from the osmotic data of Wu and Hamer (1980) extending to $\mathrm{NaNO}_{3}$ saturation (i.e. $10.83 \mathrm{~m}$ ) and at $100^{\circ} \mathrm{C}$ from the osmotic data of Voigt et al. (1990) extending to $12.2 \mathrm{~m}$. These two sets of values were then used to determine the coefficients for $\mathrm{NaNO}_{3}$ given in Table 1 .

The coefficients in eqn(2) for the parameters for silicic acid ioninteractions are summarized in Table 2. In determining these parameters the solubility data in the various salt solutions were determined isothermally and 
TABLE 2. Coefficients for the temperature-dependent expression for $\mathrm{H}_{4} \mathrm{SiO}_{4}$ ion-interaction parameters.

Parameter

$\lambda\left(\mathrm{H}_{4} \mathrm{SiO}_{4}-\mathrm{NO}_{3}^{-}\right)$

$\lambda\left(\mathrm{H}_{4} \mathrm{SiO}_{4}-\mathrm{Na}^{7}\right)$

$\lambda\left(\mathrm{H}_{4} \mathrm{SiO}_{4}-\mathrm{Cl}^{-}\right)$

$\lambda\left(\mathrm{H}_{4} \mathrm{SiO}_{4}^{4}-\mathrm{SO}_{4}^{2-}\right)$

$\lambda\left(\mathrm{H}_{4} \mathrm{SiO}_{4}^{4}-\mathrm{Mg}^{2+}\right)$

$\zeta\left(\mathrm{H}_{4}^{4} \mathrm{SiO}_{4}^{4}-\mathrm{H}^{+}-\mathrm{NO}_{3}^{-}\right)$

$\zeta\left(\mathrm{H}_{4}^{4} \mathrm{SiO}_{4}^{4}-\mathrm{Na}^{+}-\mathrm{Cl}^{-}\right)$

$\zeta\left(\mathrm{H}_{4} \mathrm{SiO}_{4}-\mathrm{Mg}^{2+}-\mathrm{Cl}^{-}\right)$ $\underline{a}_{1}$

$\underline{\mathrm{a}}_{2}$

$9.2844972 \mathrm{e}+01 \quad 1.197600 \mathrm{e}-0$

$-1.142800 \mathrm{e}-011.186670 \mathrm{e}-04$

$-4.394000 \mathrm{e}-021.295300 \mathrm{e}-03$

$-8.737600 \mathrm{e}-02 \quad 5.533300 \mathrm{e}-04$

$6.2274500 e-01-1.81330 e-03$ $-0.0033$

$5.9630 \mathrm{e}-02-2.00000 \mathrm{e}-04$

$-2.2861 \mathrm{e}-01$

$5.94133 e-04$ $\underline{a}_{4} \quad \underline{a}_{6}$

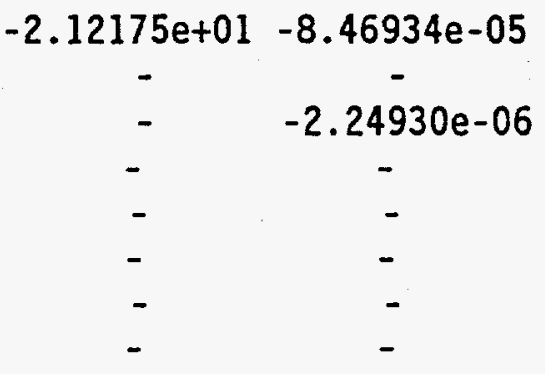

the coefficients for eqn(2) determined by fitting the calculated parameter values at different temperatures.

The most difficult parameter to determine was the standard chemical potential of $\mathrm{SiO}_{2}(\mathrm{am})$. This parameter is primarily determined by the dilute solution solubility. Determining the dilute solution solubility of amorphous silica from different batches of starting material has always been difficult and has been discussed in length by Marshall (1980a). Briefly, differences in particle size and possibly lack of attainment of equilibrium at lower temperatures appear to be part of the problem. The net result of this difficulty is that different dilute solution solubilities and, hence, different calculated standard chemical potentials of $\mathrm{SiO}_{2}(\mathrm{am})$ are determined or extrapolated from different electrolyte solutions. The tabulated best fit values for the standard chemical potential of $\mathrm{SiO}_{2}(\mathrm{am})$ at various temperatures are given in Table 3 . These values are used in all subsequent calculations except for the case of $\mathrm{Na}_{2} \mathrm{SO}_{4}$ solutions at $25^{\circ} \mathrm{C}$ where the standard chemical potential of $\mathrm{SiO}_{2}(\mathrm{am})$ was independently determined. The values shown in Table 3 all assume $\mu^{\circ} / \mathrm{RT}$ for $\mathrm{H}_{4} \mathrm{SiO}_{4}(\mathrm{aq})=-531.121$, the value at $25^{\circ} \mathrm{C}$ given by Wagman et al. (1982).

The following section presents a detailed comparison of the calculated and experimental amorphous silica solubilities over the temperature range 25$100^{\circ} \mathrm{C}$. 
TABLE 3. Calculated values of the standard chemical potential of $\mathrm{SiO}_{2}(\mathrm{am})$ at different temperatures.

\begin{tabular}{cl} 
Temperature $\left({ }^{\circ} \mathrm{C}\right)$ & $\underline{\mu} / \mathrm{RT}$ \\
\hline $22-23$ & -346.184 \\
25 & -345.900 \\
36 & -347.410 \\
47 & -348.645 \\
65 & -350.250 \\
95 & -352.396 \\
100 & -352.800
\end{tabular}

\section{RESULTS AND DISCUSSION}

A comparison of our experimental results for $\mathrm{NaNO}_{3}$ with those of Marshall (1980a) were presented in Silva et al. (1993) and is reproduced here (see Figure 1) for the convenience of the reader and to demonstrate the consistency between the two sets of experimental measurements.

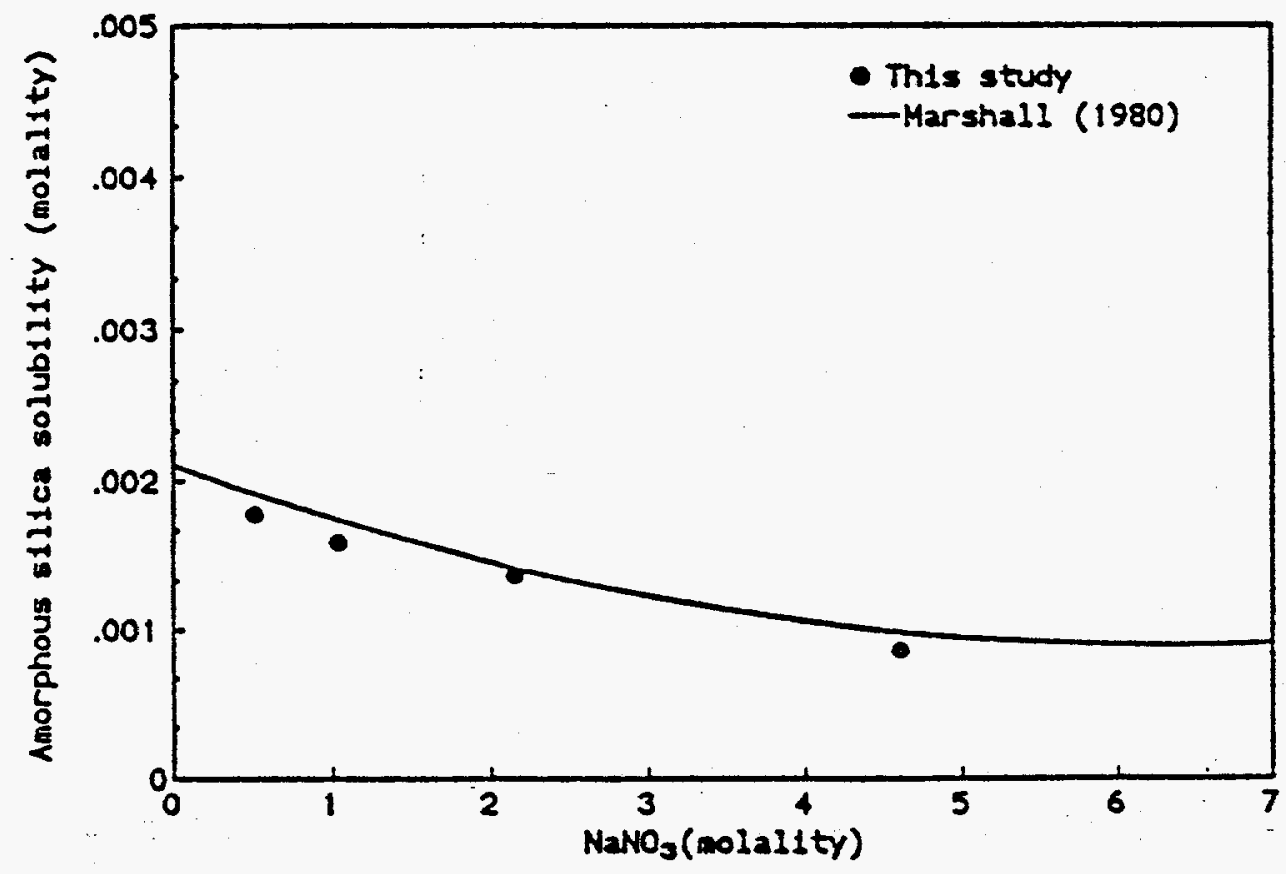

Figure 1. Comparison of Amorphous Silica Solubilities in $\mathrm{NaNO}_{3}$. 
The experimental and calculated solubilities of amorphous silica in $\mathrm{HNO}_{3}$ solutions are shown in Figure 2. The difficulty in determining a definitive value for the dilute solution solubility of amorphous silica is clearly exhibited in Figure $2 a$ where the experimental solubilities can vary by approximately $15 \%$. The standard chemical potential of $\mathrm{SiO}_{2}(\mathrm{am})$ as well as the ion-interaction parameters for $\mathrm{H}_{4} \mathrm{SiO}_{4}(\mathrm{aq})$ (i.e., $\mathrm{AH}_{4} \mathrm{SiO}_{4}-\mathrm{NO}_{3}^{--}$and $\mathrm{AH}_{4} \mathrm{SiO}_{4}-\mathrm{NO}_{3}^{--}-$ $\mathrm{H}^{+}$) were determined in each data set.

In determining these parameters, the value of $\lambda\left(\mathrm{H}_{4} \mathrm{SiO}_{4}-\mathrm{NO}_{3}^{--}\right)$was first fit, along with the standard chemical potential of $\mathrm{SiO}_{2}(\mathrm{am})$ from the data at $\mathrm{HNO}_{3}$ concentrations $<5 \mathrm{~m}$. The value of $\zeta\left(\mathrm{H}_{4} \mathrm{SiO}_{4}-\mathrm{NO}_{3}^{--}-\mathrm{H}^{+}\right)$was then adjusted to fit the data at higher concentration. The value of $\lambda\left(\mathrm{H}_{4} \mathrm{SiO}_{4}-\mathrm{H}^{+}\right)$was set to zero at all temperatures by convention.

The experimental and calculated amorphous silica solubilities in $\mathrm{NaNO}_{3}$ solutions are shown in Figure 3 . The values of $\lambda\left(\mathrm{H}_{4} \mathrm{SiO}_{4}-\mathrm{NO}_{3}{ }^{-}\right)$calculated from the $\mathrm{HNO}_{3}$ data were used in these calculations. Only the standard chemical potential of $\mathrm{SiO}_{2}(\mathrm{am})$ and $\lambda\left(\mathrm{H}_{4} \mathrm{SiO}_{4}-\mathrm{Na}^{+}\right)$was adjusted. No higher order $\lambda\left(\mathrm{H}_{4} \mathrm{SiO}_{4}-\mathrm{Na}^{+}-\mathrm{NO}_{3}^{-}\right)$parameter was required. The calculated and experimental values are in good agreement.

The experimental and calculated amorphous silica solubilities in $\mathrm{HCl}$ solutions are shown in Figure 4. In these calculations the standard chemical potential of $\mathrm{SiO}_{2}(\mathrm{am})$. was fixed at the values obtained from analysis of the $\mathrm{HNO}_{3}$ data. The only adjusted parameter was $\lambda\left(\mathrm{H}_{4} \mathrm{SiO}_{4}-\mathrm{Cl}^{-}\right)$. No higher order $\lambda\left(\mathrm{H}_{4} \mathrm{SiO}_{4}-\mathrm{Cl}^{-}-\mathrm{H}^{+}\right)$term was required.

The experimental and calculated amorphous silica solubilities in $\mathrm{NaCl}$ solutions are shown in Figure 5 . In these calculations the values of $\lambda\left(\mathrm{H}_{4} \mathrm{SiO}_{4}-\mathrm{Na}^{+}\right)$were fixed at the values determined from the data in $\mathrm{NaNO}_{3}$ solutions. In the $25^{\circ} \mathrm{C}$ calculations only the standard chemical potential of $\mathrm{SiO}_{2}(\mathrm{am})$ was adjusted. All ion-interaction parameters had previously been determined. The $25^{\circ} \mathrm{C} \mathrm{NaCl}$ solubility data, therefore, represents a partial validation of the aqueous model developed from the $\mathrm{HNO}_{3}, \mathrm{NaNO}_{3}$, and $\mathrm{HCl}$ data. In the $100^{\circ} \mathrm{C}$ calculations the standard chemical potential of $\mathrm{SiO}_{2}(\mathrm{am})$, $\lambda\left(\mathrm{H}_{4} \mathrm{SiO}_{4}-\mathrm{Cl}^{-}\right)$, and $\lambda\left(\mathrm{H}_{4} \mathrm{SiO}_{4}-\mathrm{Na}^{+}-\mathrm{Cl}^{-}\right)$was adjusted. It was necessary to 

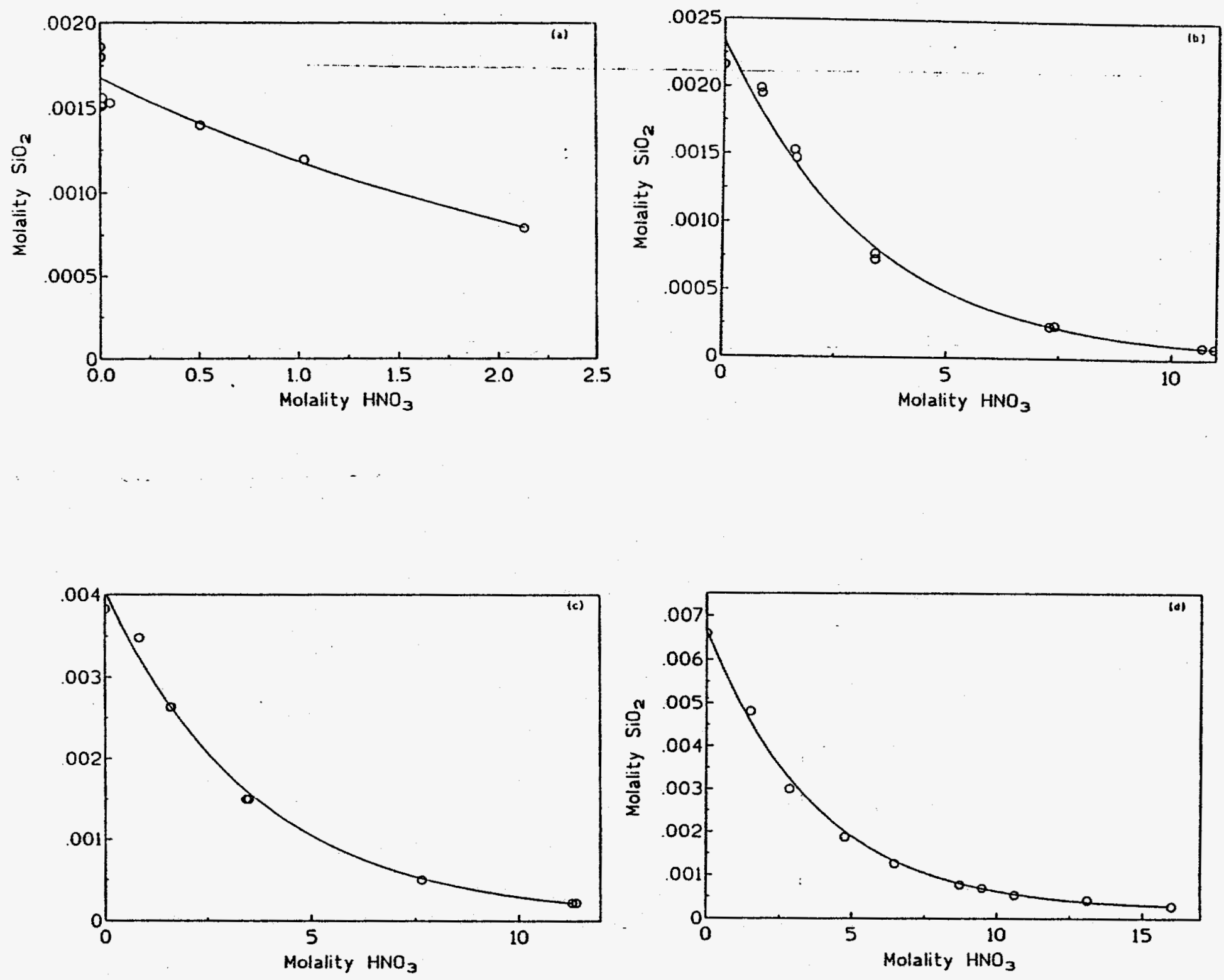

Figure 2. Experimental and Calculated Solubilities of Amorphous Silica in $\mathrm{HNO}_{3}$ solutions. (a) room temperature $\left(22-23^{\circ} \mathrm{C}\right.$ ), (b) $36^{\circ} \mathrm{C}$, (c) $65^{\circ} \mathrm{C}$, (d) $95^{\circ} \mathrm{C}$. Experimental data at room temperature determined in this study. Experimental data at other temperatures from Elmer and Nordberg (1958). 

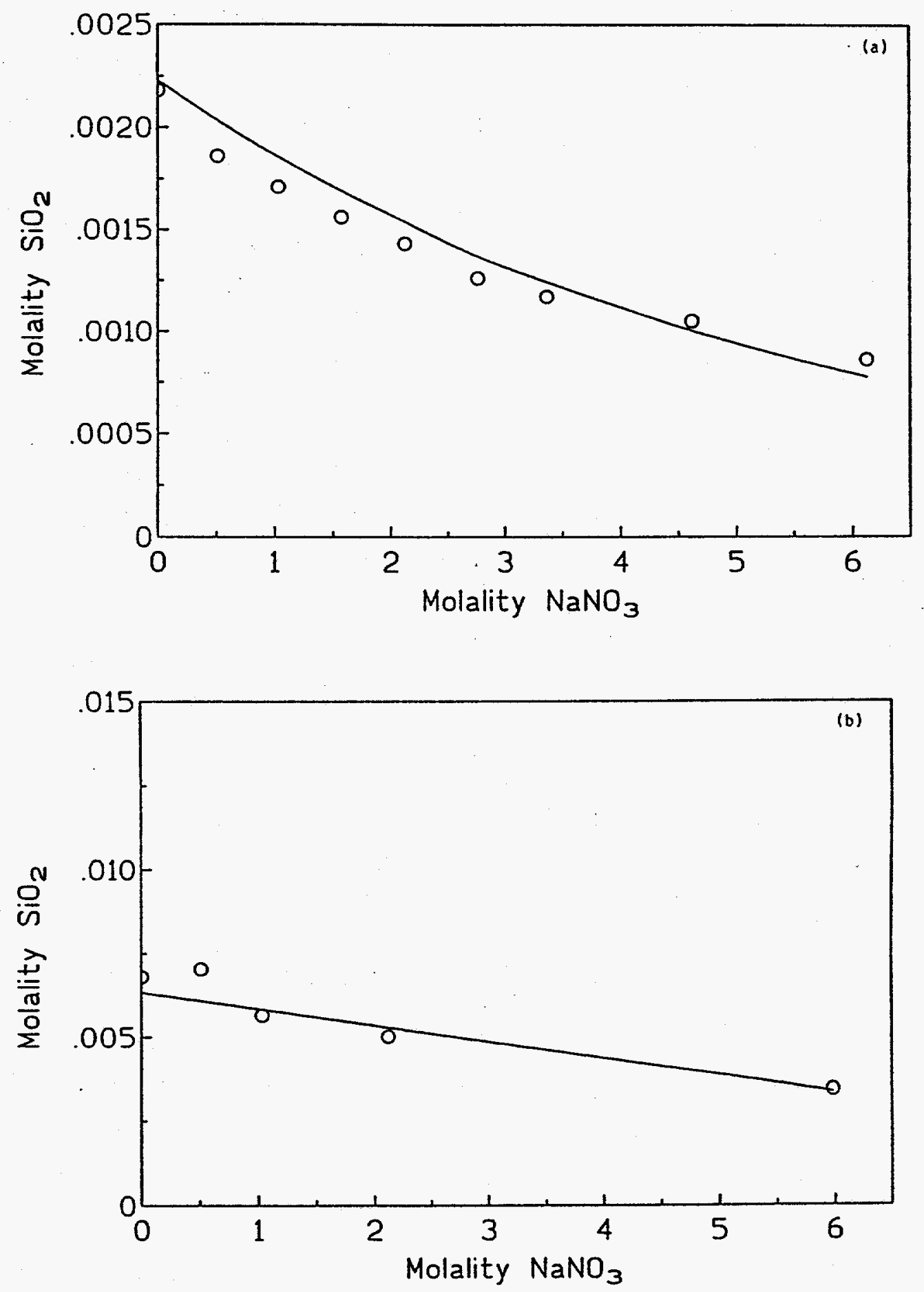

Figure 3. Experimental and Calculated Solubilities of Amorphous Silica in $\mathrm{NaNO}_{3}$ solutions. (a) $25^{\circ} \mathrm{C}$. (b) $100^{\circ} \mathrm{C}$. Experimental Data of Marshall (1980). 

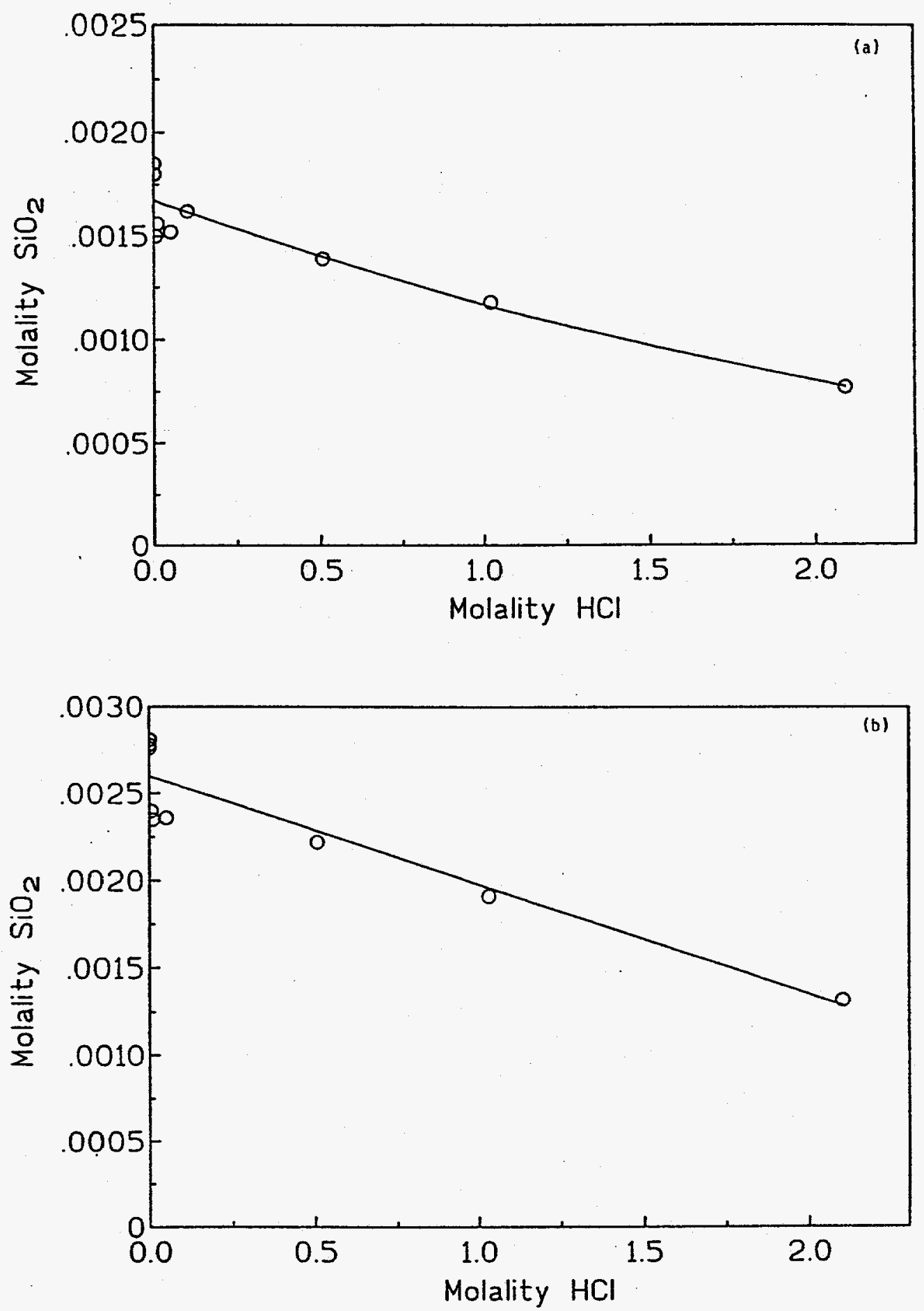

Figure 4. Experimental and Calculated Amorphous Silica Solubilities in $\mathrm{HCl}$ Solutions. Experimental data obtained as part of this study. (a) Room Temperature $\left(22-23^{\circ} \mathrm{C}\right)$. (b) $47^{\circ} \mathrm{C}$. 

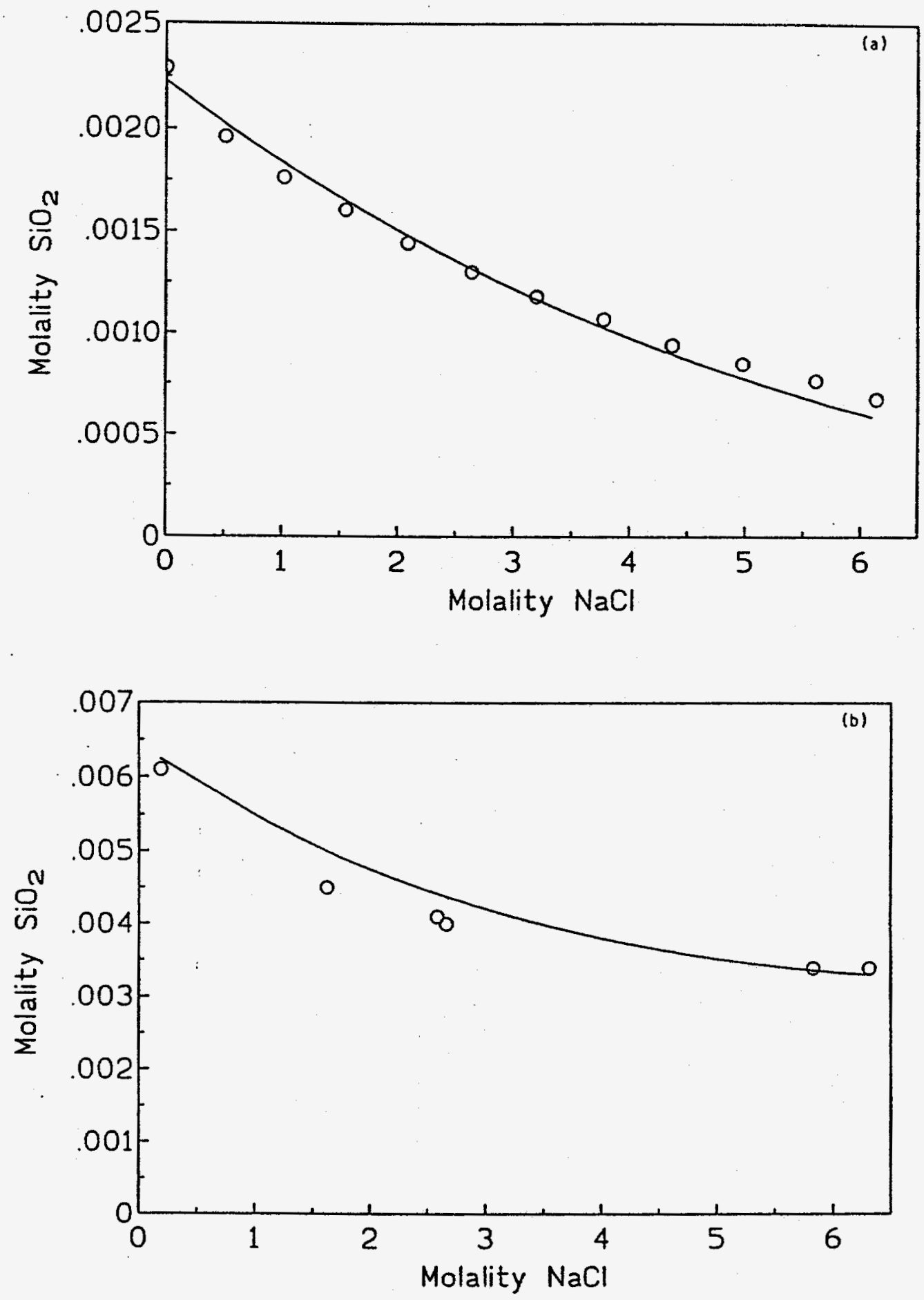

Figure 5. Experimental and Calculated Solubilities of Amorphous Silica in $\mathrm{NaCl}$ Solutions. (a) $25^{\circ} \mathrm{C}$ (Data of Marshall and Warakomski 1980). (b) $100^{\circ} \mathrm{C}$ (Data of Chen and Marshall 1982). 
determine $\lambda\left(\mathrm{H}_{4} \mathrm{SiO}_{4}-\mathrm{Cl}^{\circ}\right)$ in the $100^{\circ} \mathrm{C}$ calculations since the $\mathrm{HCl}$ solubility data extended to only $47^{\circ} \mathrm{C}$.

The experimental and calculated amorphous silica solubilities in $\mathrm{Na}_{2} \mathrm{SO}_{4}$. solutions is shown in Figure 6 . In these calculations the value of $\lambda\left(\mathrm{H}_{4} \mathrm{SiO}_{4}\right.$ $\mathrm{Na}^{+}$) determined from the $\mathrm{NaNO}_{3}$ data was used. The only adjusted parameters were the standard chemical potential of $\mathrm{SiO}_{2}(\mathrm{am})$ at $25^{\circ} \mathrm{C}$ and the values for $\lambda\left(\mathrm{H}_{4} \mathrm{SiO}_{4}-\mathrm{SO}_{4}{ }^{2-}\right)$ at $25^{\circ} \mathrm{C}$ and $100^{\circ} \mathrm{C}$. The standard chemical potential of $\mathrm{SiO}_{2}(\mathrm{am})$ at $25^{\circ} \mathrm{C}$ was refit because the extrapolated dilute solution solubility of amorphous silica in $\mathrm{Na}_{2} \mathrm{SO}_{4}$ solution does not agree with the extrapolated dilute solution solubility in $\mathrm{NaCl}$ solution. This is the only case where a model parameter was used which is different from those given in Tables 1,2 , or 3 .

The experimental and calculated amorphous silica solubilities in $\mathrm{MgSO}_{4}$ solutions are shown in Figure 7 . In these calculations the standard chemical potential of $\mathrm{SiO}_{2}(\mathrm{am})$ was fixed at the corresponding values determined from the data in $\mathrm{NaCl}$ solutions. The values for $\lambda\left(\mathrm{H}_{4} \mathrm{SiO}_{4}-\mathrm{SO}_{4}{ }^{2-}\right)$ were fixed at the values determined from the data in $\mathrm{Na}_{2} \mathrm{SO}_{4}$ solutions. The only adjusted parameter was $\left.\mathrm{\Lambda}_{4} \mathrm{H}_{4} \mathrm{SiO}_{4}-\mathrm{Mg}^{2+}\right)$.

The experimental and calculated amorphous silica solubilities in $\mathrm{MgCl}_{2}$ solutions are shown in Figure 8. Two sets of calculations are shown at $25^{\circ} \mathrm{C}$. The dashed curve represents the model predictions with no parameters adjusted. A7though this curve gives a reasonable overall representation of the data, the fit can be improved by adjusting the higher order $\lambda\left(\mathrm{H}_{4} \mathrm{SiO}_{4}-\mathrm{Mg}^{2+}-\mathrm{Cl}^{-}\right)$term.

This final model accurately represents all of the experimental data.

As a final test of our model, the solubilities of amorphous silica were calculated in mixed electrolyte solutions (Table 4, Figure 9). These results, with the possible exception of one data point in mixed $\mathrm{NaCl}_{-} \mathrm{MgCl}_{2}$, are all predicted well within the experimental error in the measurements. These final predictions represent an excellent validation of our final thermodynamic model. 

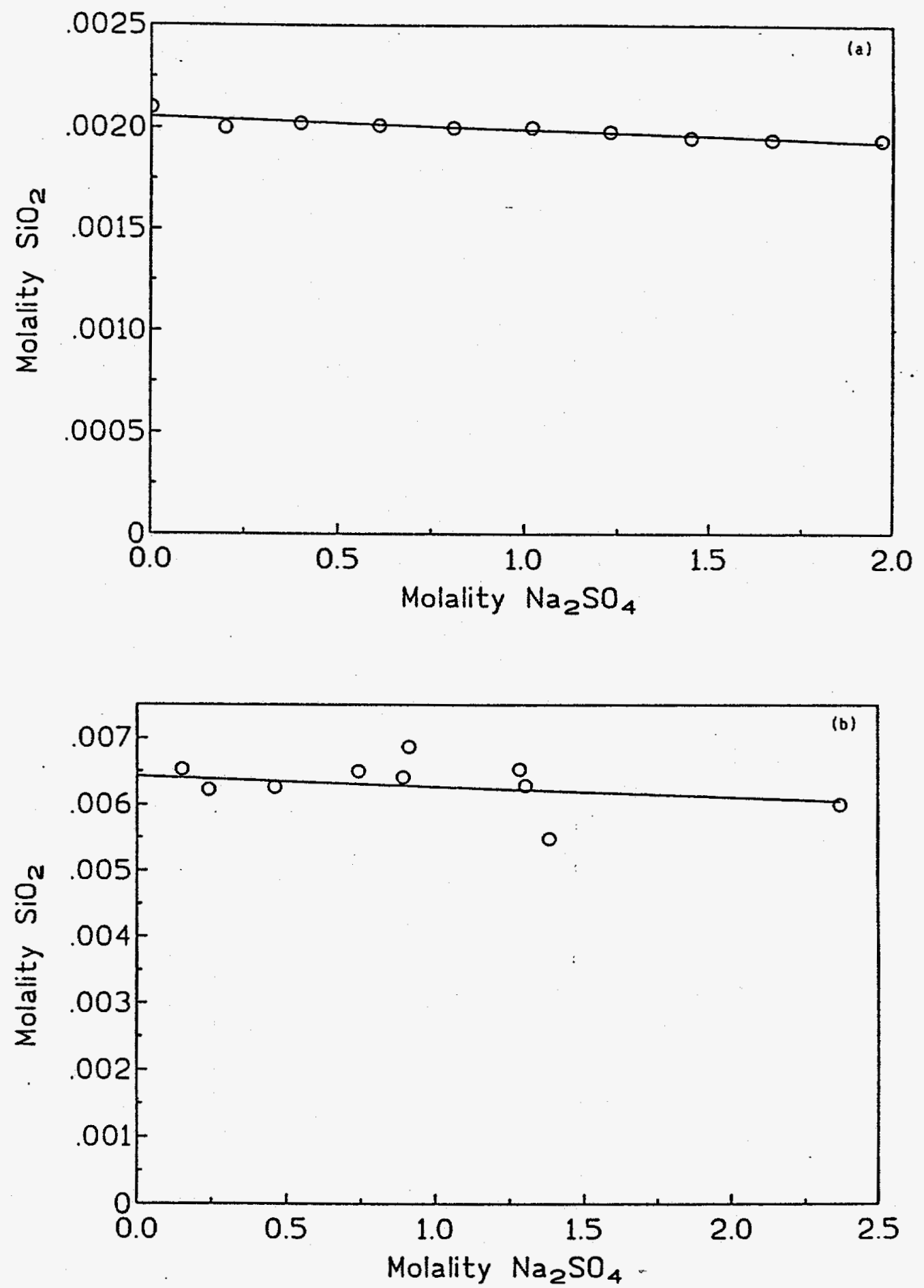

Figure 6. Experimental and Calculated Solubilities of Amorphous Silica in $\mathrm{Na}_{3} \mathrm{SO}_{4}$ Solutions. (a) $25^{\circ} \mathrm{C}$ (Data of Marshall and Warakomski 1980). (b) $100^{\circ} \mathrm{C}$ (Data of Chen and Marshall 1982). 

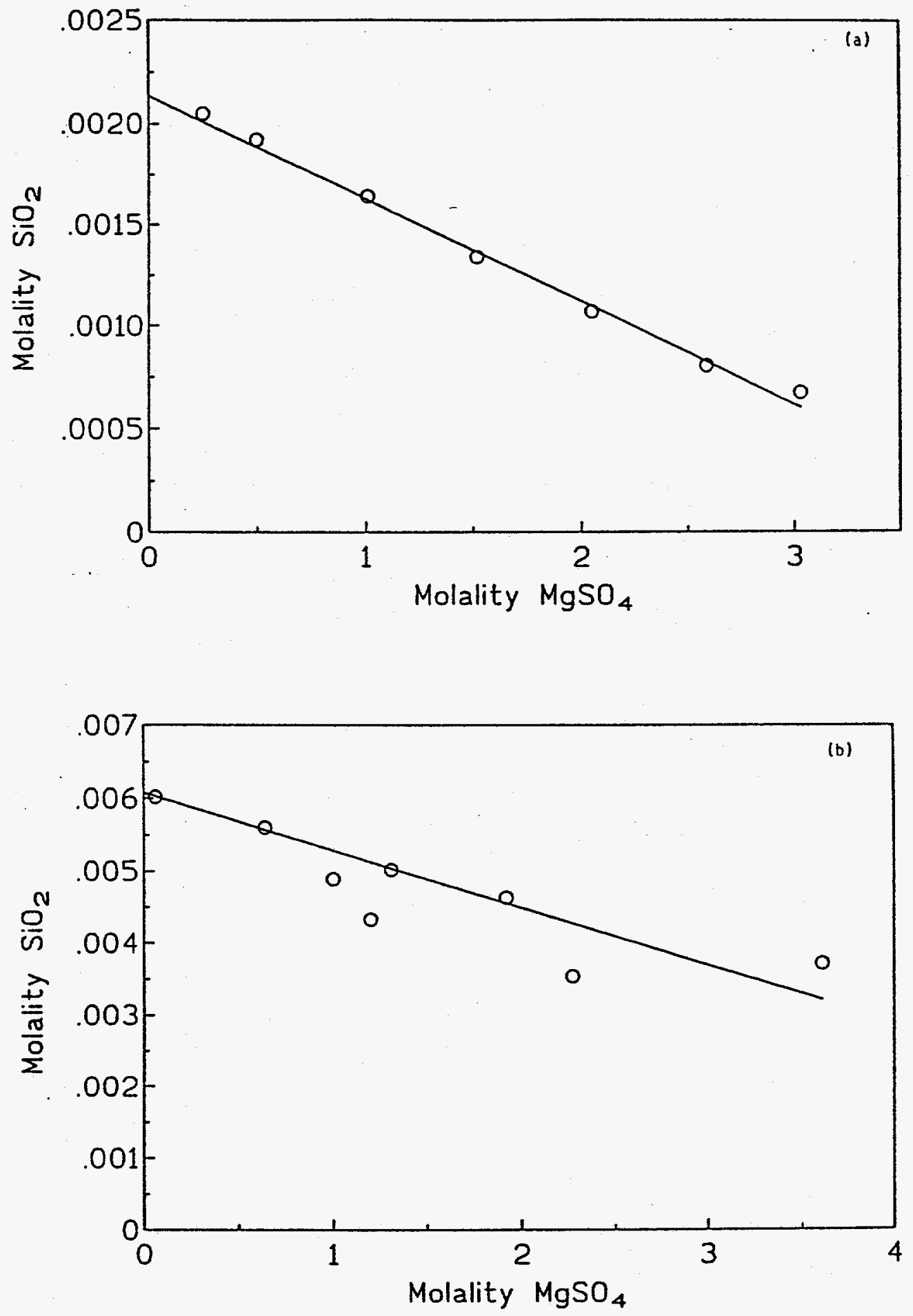

Figure 7. Experimental and Calculated Solubilities of Amorphous Silica in MgSO Solutions. (a) $25^{\circ} \mathrm{C}$ (Data of Marshall and Warakomski 1980). (b) $100^{\circ} \mathrm{C}$ (Data of Chen and Marshall 1982). 

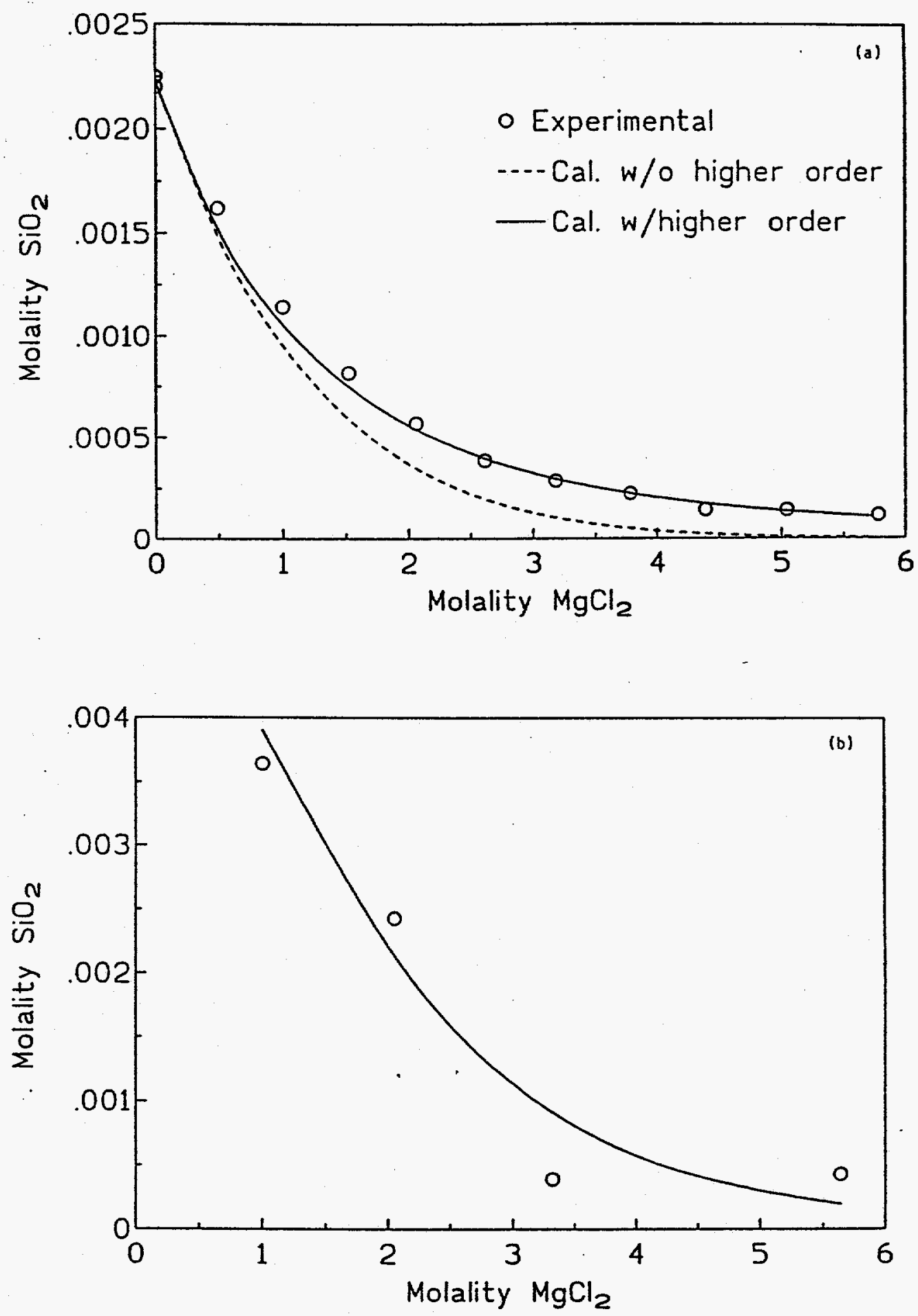

Figure 8. Experimental and Calculated Solubilities of Amorphous Silica in $\mathrm{MgCl}_{2}$ Solutions. (a) $25^{\circ} \mathrm{C}$ (Data of Marshall and Warakomski 1980). (b) $100^{\circ} \mathrm{C}$ (Data of Chen and Marshall 1982). 
TABLE 4. Experimental and calculated amorphous silica solubilities in mixed electrolyte solutions at $100^{\circ} \mathrm{C}$. Experimental data of Marshall and Chen (1982b).

Electrolytes

Experimental

$\mathrm{NaCl} \quad \mathrm{MgCl}_{2}$

$0.821 .23^{2}$

$1.23 \quad 0.66$

$\mathrm{NaCl} \quad \mathrm{MgSO}_{4}$

0.970 .96

$\begin{array}{lr}\mathrm{Na}_{2} \mathrm{SO}_{4} & \mathrm{MgCl}_{2} \\ 0.71 & 1.38\end{array}$

$\mathrm{Na}_{2} \mathrm{SO}_{4} \mathrm{MgSO}_{4}$

$0.755^{4} 0.78$

$0.90 \quad 0.40$

$\begin{array}{lll}\mathrm{MgCl}_{2} & \mathrm{MgSO}_{4}\end{array}$

$\begin{array}{ll}1.11^{2} & 0.38\end{array}$

0.0038
0.0046

0.0045

0.0031

0.0033

0.0055

0.0055

0.0055

0.0059

0.0036

0.0035 


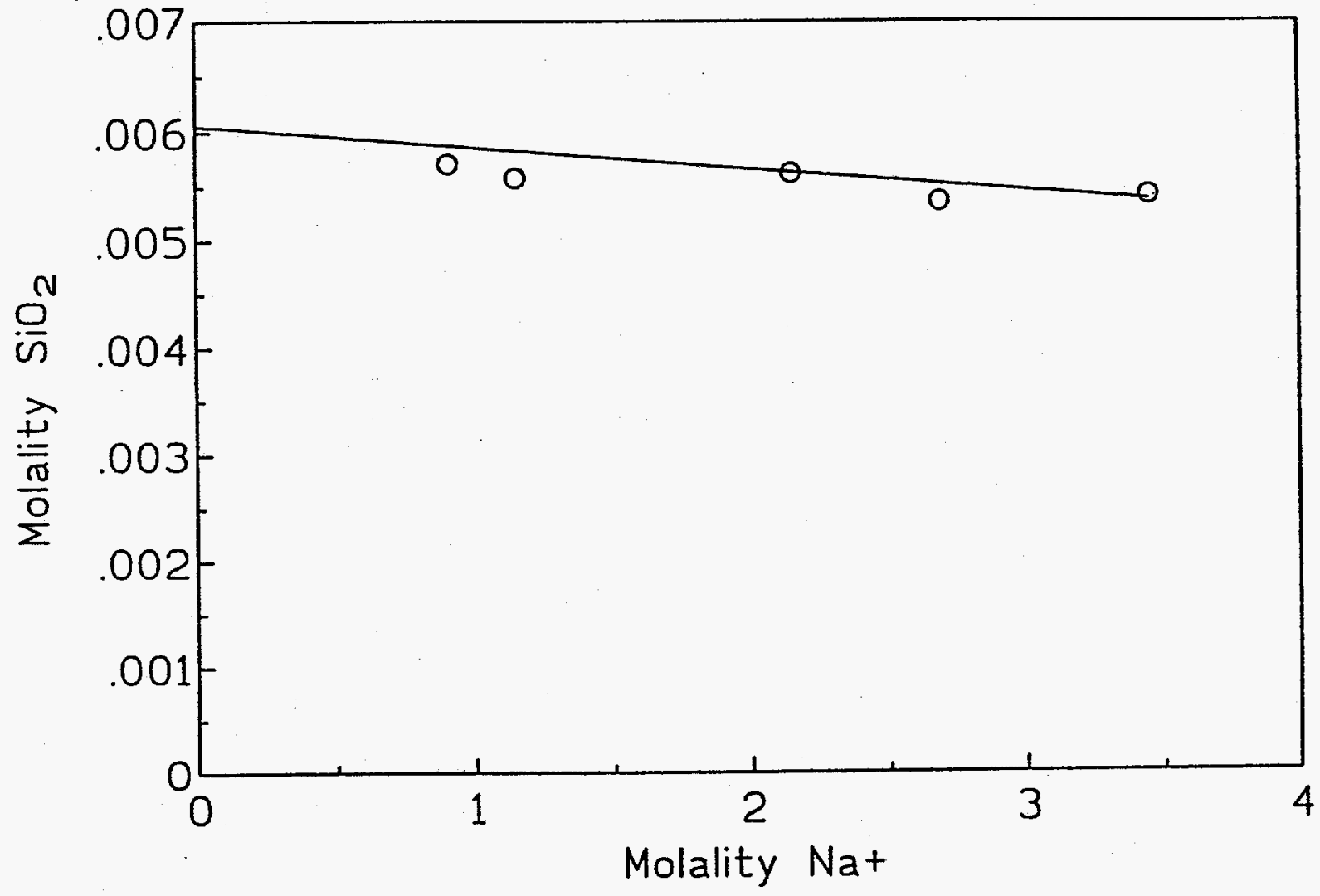

Figure 9. Experimental and Calculated Solubilities of Amorphous Silica in mixed $\mathrm{NaCl}$ and $\mathrm{Na}_{2} \mathrm{SO}_{4}$ solutions at $100^{\circ} \mathrm{C}$. Experimental Data of Marshall and Chen (1982b). 


\section{REFERENCES}

Chen, C.A. and W.L. Marshall (1982). Amorphous silica solubilities IV. Behavior in pure water and aqueous sodium chloride, sodium sulfate, magnesium chloride, and magnesium sulfate solutions up to $350^{\circ} \mathrm{C}$. Geochim. Cosmochim. Acta: $46,279-287$.

Clegg, S.L. and P. Brimblecombe (1990). Equilibrium partial pressures and mean activity coefficients of $0-100 \%$ nitric acid as a function of temperature. J. Phys. Chem.: $94(13), 5369-5380$.

De Lima, M.C.P. and K.S. Pitzer (1983). Thermodynamics of saturated electrolyte mixtures of $\mathrm{NaCl}$ with $\mathrm{Na}_{2} \mathrm{SO}_{4}$ and $\mathrm{MgCl}_{2}$. J. Solution Chem.: 12, 187-199.

Elmer, T. H. and M.E. Nordberg (1958). Solubility of silica in nitric acid solutions. J.Am. Ceramic Soc.: 41(12), 517-520.

Felmy, A.R. and J.H. Weare (1986). The prediction of borate mineral equilibria in natural waters: Application to Searles lake, California. Geochim. Cosmochim. Acta: 50, 2771-2783.

Felmy, A.R., D. Rai, J.A. Schramke, and J.L. Ryan (1989). The solubility of plutonium hydroxide in dilute solution and in high-ionic-strength chloride brines. Radiochimica Acta: 48, 29-35.

Greenberg, J.P. and N. M $\$ 17$ er (1989). The prediction of mineral solubilities in natural waters: A chemical equilibrium model for the $\mathrm{Na}-\mathrm{K}-\mathrm{Ca}-\mathrm{Cl}-\mathrm{SO}_{2}-\mathrm{H}_{2} \mathrm{O}$ system to high concentration from 0 to $250^{\circ} \mathrm{C}$. Geochim. Cosmochim. Acta: 53 , 2503-2518.

Holmes, H.F., R.H. Busey, J.M. Simonson, R.E. Mesmer, D.G. Archer, and R.H. Wood (1987). The enthalpy of dilution of $\mathrm{HCl}(\mathrm{aq})$ to $648 \mathrm{~K}$ and $40 \mathrm{MPa}$ Thermodynamic Properties. J. Chem. Thermodynamics: 19, 863-890.

Marshall, W.L. (1980a). Amorphous silica solubilities-I. Behavior in aqueous sodium nitrate solutions: $23-300^{\circ} \mathrm{C}, 0-6 \mathrm{molal}$. Geochim. Cosmochim. Acta: $44(7), 907-913$.

Marshall, W.L. (1980b). Amorphous silica solubilities-III. Activity coefficient relations and predictions of solubility behavior in salt solutions, $0-350^{\circ} \mathrm{C}$. Geochim. Cosmochim. Acta: 44 ; 925-931.

Marshall, W.L. and C.T.A. Chen (1982a). Amorphous silica solubilities V. Predictions of solubility behavior in aqueous mixed electrolyte solutions to $300^{\circ} \mathrm{C}$. Geochim. Cosmochim. Acta: 46, 289-291. 
Marsha11, W.L. and C.T.A. Chen (1982b). Amorphous silica solubilities VI. Opostulated sulfate-silicic acid solution complex. Geochim. Cosmochim. Acta: $46,367-370$.

Marsha11, W.L. and J.M. Warakomski (1980). Amorphous silica solubilities-II. Effect of aqueous salt solutions at $25^{\circ} \mathrm{C}$. Geochim. Cosmochim. Acta: $44(7)$, 915-924.

M $\phi 1$ ler, N. (1988). The prediction of mineral solubilities in natural waters: A chemical equilibrium model for the $\mathrm{Na}-\mathrm{Ca}-\mathrm{Cl}-\mathrm{SO}_{4}-\mathrm{H}_{2} \mathrm{O}$ system, to high temperature and concentration. Geochim. Cosmochim. Acta: 52, 821-837.

Pitzer, K.S. (1979). Theory: Ion interaction approach, Ch. 7 in Activity Coefficients in Electrolyte Solutions, R.M. Pytckowicz ed., CRC Press, Boca Raton, FL.

Silva, L.J., A.R. Felmy, and E.R. Ding (1993). Sludge treatment evaluation: 1992 technical progress. PNL-8403, Pacific Northwest Laboratories, Richland WA.

Voigt, W., A. Dittrich, B. Haugsdal, and K. Grjotheim. (1990). Thermodynamics of aqueous reciprocal salt systems. III. Isopiestic determination of osmotic and activity coefficients in $\mathrm{LiNO}_{3}-\mathrm{NaBr}-\mathrm{H}_{2} \mathrm{O}$ and $\mathrm{LiBr}-\mathrm{NaNO}_{3}-\mathrm{H}_{2} \mathrm{O}$ at $100.3^{\circ} \mathrm{C}$. Acta Chemica Scandinavica: $44,12-17$.

Wagman, D.D., W.H. Evans, V.B. Parker, R.H. Schumm, I. Halow, S.M. Bailey, K.L. Churney, and R.L. Nuttall (1982). The NBS tables of chemical thermodynamic properties. Selected values for inorganic and $C_{1}$ and $C_{2}$ organic substances in SI units. J. Phys. Chem. Ref. Data: 11 (Supplement 2).

Wu, Y.C. and W.J. Hamer (1980). Revised values of the osmotic coefficients and mean activity coefficients of sodium nitrate in water at $25^{\circ} \mathrm{C}$. $\mathrm{J}$. Phys. Chem. Ref. Data: $9(2), 513-518.2$ 